\title{
A Study to Compare the Immediate Effects of Inverse Ratio Breathing and Diaphragmatic Breathing on Pulmonary Functions and Thoracic Expansion in Patients with Chronic Obstructive Pulmonary Disease
}

\author{
Bharvi Malavia', Sweety $\operatorname{Shah}^{2}$ \\ ${ }^{1}$ MPT, Assistant Professor, Khyati College of Physiotherapy, Palodia, Ahmedabad, Gujarat, India \\ ${ }^{2} \mathrm{Ph}$. D, MPT, Lecturer, SBB College of Physiotherapy, VS General Hospital, Ahmedabad, Gujarat, India
}

Corresponding Author: Bharvi Malavia

\begin{abstract}
Background: COPD leads to airway obstruction, hyperinflation, mechanical disadvantage of respiratory muscles which places accessory muscles in shortened position, leading to increase resistance to chest wall expansion, this causes decrease in pulmonary function. Breathing exercises assist by decreasing dyspnea. Diaphragmatic breathing aims to improve chest wall motion and distribution of ventilation. In Inverse ratio breathing, the ratio of I:E becomes 2:1. This study aims to compare the immediate effects of diaphragmatic and inverse ratio breathing in patients with COPD.

Method: Study was conducted on 60 patients having COPD. Subjects were randomly selected to perform diaphragmatic or inverse ratio breathing first on day 1 , and other technique on day 2 . Diaphragmatic breathing was performed for total duration of 5 minutes within 10 minute interval at 68 breathes/minute. Washout period of one day was given. Next day, subject was asked to perform inverse ratio breathing using visual video feedback (inspiration for 4 seconds and expiration for 2 seconds) for 10 minutes.

Outcome measures: Pulmonary functions (FVC, $\left.\mathrm{FEV}_{1}, \mathrm{FEV}_{1} / \mathrm{FVC}, \mathrm{MVV}\right)$ and thoracic expansion at $2^{\text {nd }}, 4^{\text {th }}, 6^{\text {th }}$ intercostal space

Results: Result showed significant improvement for FVC, $\mathrm{FEV}_{1}$ and MVV, but $\mathrm{FEV}_{1} / \mathrm{FVC}$ shows no significant difference after diaphragmatic breathing. There was no significant difference for pulmonary functions after inverse ratio breathing. Results showed no significant difference for thoracic expansion after either of two breathing techniques.

Conclusion: Diaphragmatic breathing showed significant improvement in pulmonary functions, however no improvement was observed in thoracic expansion. Inverse ratio breathing showed no improvement in pulmonary functions or thoracic expansion.
\end{abstract}

Keywords: COPD, diaphragmatic breathing, inverse ratio breathing, pulmonary functions, thoracic expansion

\section{INTRODUCTION}

Recently ATS/ERS jointly defined Chronic Obstructive Pulmonary Disease (COPD) as "a preventable and treatable disease state characterized by airflow limitation that is not fully reversible" ${ }^{[1]}$. The two major components of COPD are chronic bronchitis ${ }^{[2,3]}$ and pulmonary emphysema $[3,4]$.

COPD is one of the most important causes of morbidity and mortality worldwide ${ }^{[5]}$ representing the largest fraction of mortality for respiratory diseases, which are the third most common cause of 
Bharvi Malavia et.al. A study to compare the immediate effects of inverse ratio breathing and diaphragmatic breathing on pulmonary functions and thoracic expansion in patients with chronic obstructive pulmonary disease.

death $(8 \%)$ in the 25 member states of the European Union (EU) ${ }^{[6]}$.

As on 2016, three out of five leading causes of mortalities constitute noncommunicable diseases whereas COPD is the second biggest cause of death in India today ${ }^{[7]}$.

Patients with COPD develop changes in chest wall configuration. These changes are related to airway obstruction, hyperinflation, and mechanical disadvantage of respiratory muscles. Reduced upper limb activity leads to disuse which causes muscle tightening and stiffness thereby further increasing chest wall resistance and work of breathing $^{[8]}$. The hyperinflated lungs places the pectoralis major in a shortened position, which leads to increase in resistance to chest wall to expand, this causes a decrease in exercise capacity and pulmonary function [9].

In patients with severe COPD, mechanical efficiency of respiratory muscles causes decreased rib cage motion and increase abdominal motion leading to paradoxical pattern of breathing ${ }^{[10]}$ which is common in diaphragm dysfunction. Due to dysfunction of diaphragm, accessory muscles of respiration play a major role. The activity of these muscles elevates shoulder girdle and increases vertical motion of the rib cage during the inspiratory phase of breathing. Retraction of these soft tissues and muscles around the chest wall limits the chest expansion ${ }^{[11]}$. Due to the accessory muscle tightness in COPD patients, chest expansion is decreased, where the rib cage movement is also reduced which leads to hyperinflation, leading to a chronic reduction of the opposition zone of the diaphragm.

Persons with COPD are greatly under estimated because the disease is usually not diagnosed until it is moderately advanced. Dyspnea is often progressive, and initially occurs with exertion, gradually interferes with daily activities and in late stages dyspnea may be present at rest also. The person becomes more of a chest breather, relying on the intercostals and accessory muscles rather than effective abdominal breathing.

Breathing exercises may assist the patient during rest and activity by decreasing dyspnea, improving oxygenation, and slowing the respiratory rate.

Some reports have shown diaphragmatic breathing to cause a significant increase in tidal volume, reduction in respiratory rate, and improved breathing pattern and respiratory efficiency in COPD patients ${ }^{[12,13]}$.

During diaphragmatic breathing the patient is told to move the abdominal wall predominantly during inspiration and to reduce upper rib cage motion. This aims to improve chest wall motion and the distribution of ventilation, to decrease the energy cost of breathing, the contribution of rib cage muscles and dyspnea and to improve exercise performance.

Respiration can be controlled voluntarily and one can hyperventilate or hypoventilate till serious derangements in $\mathrm{PCO}_{2}, \mathrm{PH}, \mathrm{PO}_{2}$ Occur in the blood. Inspiration can be prolonged till the tidal volume increases to more than three times the normal after which the stretch receptors in the lungs are activated and the inspiratory signals are shut off. In this manner one can prolong the duration of inspiration such that it becomes double the duration of expiration. This is called as inverse ratio breathing (IRB) in which the ratio of inspiration to expiration (I: E) becomes $2: 1^{[14]}$. To prolong inspiration in such manner the work of the external intercostal muscles increases to further increase the volume of the thoracic cavity than relaxed breathing.

Previously, studies have been carried out to find out the effects of inverse ratio breathing as a setting with different ventilator modes on cardio respiratory parameters in severe respiratory failure, ${ }^{[15]}$ in healthy individuals ${ }^{[16]}$ as well as to study benefits of inverse ratio ventilation in patients with Acute Respiratory Distress Syndrome ${ }^{[17]}$ but consciously training 
Bharvi Malavia et.al. A study to compare the immediate effects of inverse ratio breathing and diaphragmatic breathing on pulmonary functions and thoracic expansion in patients with chronic obstructive pulmonary disease.

subjects with COPD with inverse ratio and diaphragmatic breathing and comparing their immediate effects is not much studied to the best of author's knowledge.

In a patient with COPD, I: E ratio reverses due to pathology. Its effect is predominantly seen on lung and its function causing significant decrease in the pulmonary capacity and thoracic expansion. The hyperinflated lungs cause diaphragm inefficiency by placing it in a shortened position causing weakness and mechanical disadvantage which leads to reduced lung capacity and dyspnea.

Breathing exercises are thought to increase the pulmonary functions and chest expansion in the long term but its immediate effects have to be known.

So it is necessary to find out whether a single session of breathing exercise is effective in increasing lung capacity and chest expansion.

Due to the increasing prevalence of COPD, it is necessary to find adjunct breathing exercises which could help relieve dyspnea with immediate effect.

Inverse ratio breathing is thought to improve oxygenation and have advantageous effect on lung mechanics. Considering the proposed mechanisms by which inverse ratio breathing can be beneficial and the fact that it can be carried out voluntarily, it was hypothesized that inverse ratio breathing may affect the lung capacities.

This study aims to compare the immediate effects of inverse ratio breathing and diaphragmatic breathing on pulmonary functions and thoracic expansion in patients with chronic obstructive pulmonary disease (COPD).

MATERIALS AND METHODS

Study type: Interventional

Study design: Crossover study

Study setting: Department of Physiotherapy, VS General Hospital, Ahmedabad, Gujarat

Sample size: 60
Sampling technique: Convenience sampling

Study population: Patients with mild and moderate severity of chronic obstructive pulmonary disease

Study duration: 1 year

Inclusion criteria ${ }^{[18]}$ : Patients diagnosed with COPD by physician (The diagnosis was be done according to the American Thoracic Society (ATS) guidelines ${ }^{[5]}$, age 40- 70 years, both male and female, not involved in any other physiotherapy treatment, patients who are willing to participate, patients who are able to follow command.

Exclusion criteria ${ }^{[18]}$ : Acute exacerbation in the last 6 weeks, presence of any other respiratory conditions, presence of orthopaedic conditions such as scoliosis, kyphosis, presence of neuromuscular conditions such as spinal cord injury, critically ill (i.e. severe $\left(30 \% \leq \mathrm{FEV}_{1}<50 \%\right.$ predicted) and very severe $\left(\mathrm{FEV}_{1}<30 \%\right.$ predicted)).

Outcome measures: Pulmonary function tests: Forced vital capacity (FVC), Forced Expiratory Volume in one second $\left(\mathrm{FEV}_{1}\right)$, $\mathrm{FEV}_{1} / \mathrm{FVC}, \quad$ Maximum Voluntary Ventilation (MVV)

Thoracic expansion at $2^{\text {nd }}, 4^{\text {th }}$ and $6^{\text {th }}$ intercostal spaces

Materials used in the study: Pen, paper, data collection sheet, consent form, plinth, chair, RMS spirometer Helios 401, nose clip, mouth piece, inelastic measuring tape, weighing scale, stadiometer, visual video feedback

Procedure: After the approval of the ethical committee, the study was conducted on 60 patients having COPD who met the inclusion criteria. The individuals were explained of the purpose and procedure of the study. Those who were willing to participate were asked to sign a written consent form. The subjects were randomly divided in order 1 and order 2, who 
Bharvi Malavia et.al. A study to compare the immediate effects of inverse ratio breathing and diaphragmatic breathing on pulmonary functions and thoracic expansion in patients with chronic obstructive pulmonary disease.

performed either diaphragmatic breathing or inverse ratio breathing first on day 1 , and then the other technique on day 2.

Prior to administering of the breathing techniques, pulmonary function tests $^{[19]}\left(\mathrm{FVC}, \mathrm{FEV}_{1}, \mathrm{FEV}_{1} / \mathrm{FVC}, \mathrm{MVV}\right)$ and thoracic expansion at $2^{\text {nd }}, 4^{\text {th }}$ and $6^{\text {th }}$ intercostal spaces (ICS) were obtained. After recording the parameters, the patient was asked to perform diaphragmatic breathing ${ }^{[20]}$ for a total duration of 5 minutes within a 10 minute interval at 6-8 breathes per minute. The patient was made to achieve the semi- fowler's position and asked to relax the shoulder and neck muscles. They were told to place their hands just below the anterior costal margin. Instruction was given to breathe in slowly and deeply through the nose allowing the abdomen to rise and then exhale slowly through the mouth. The parameters were measured again and recorded. A washout period of one day was given.

On the next day, on the same patient, the parameters of pulmonary function tests and thoracic expansion were measured. The patient was made to sit upright on a chair and asked to carry out inverse ratio breathing using a visual video feedback (inspiration for 4 seconds and expiration for 2 seconds) for 10 minutes. These breathing techniques were performed for 1 minute, followed by 1 minute of rest, again breathing technique for 1 minute followed by 1 minute of rest for a total of 10 minutes. Hence the technique was carried out for a total duration of 5 minutes and rest given for 5 minutes during the total 10 minute duration.

\section{STATISTICAL ANALYSIS}

Statistical analysis was done using SPSS version 16. Confidence interval was kept at $95 \%$ and level of significance was kept at 0.05 . Before applying statistical tests, the data was screened for normal distribution. Shapiro- Wilk test was applied to check the normality. Data for pulmonary functions i.e. $\mathrm{FVC}, \mathrm{FEV}_{1}, \mathrm{FEV}_{1} / \mathrm{FVC}$ and MVV were normally distributed, so parametric tests (Paired t- test for analysis of pre and post intervention and Unpaired ttest for analysis of the two interventions) were used where as the data for chest expansion at $2^{\text {nd }}, 4^{\text {th }}$ and $6^{\text {th }}$ intercostals space were not normally distributed, so nonparametric tests (Wilcoxon test for analysis of pre and post intervention and Mann Whitney $U$ test for analysis of the two interventions) were used

\section{RESULTS}

A total of 72 subjects participated in the study of which 60 completed the study i.e. there were 12 dropouts. All the 60 subjects performed diaphragmatic and inverse ratio breathing on consecutive days in random order.

Table 1: Demographic data of participants

\begin{tabular}{|l|l|l|}
\hline CHARACTERISTICS & MEAN & SD \\
\hline AGE (years) & 55.68 & 7.97 \\
\hline HEIGHT (cm) & 161.00 & 8.63 \\
\hline WEIGHT (kg) & 58.80 & 14.97 \\
\hline BMI (kg/m $\mathbf{2}^{\mathbf{2}}$ & 22.82 & 6.35 \\
\hline
\end{tabular}

Table 2: Gender distribution and smoking

\begin{tabular}{|c|c|c|c|}
\hline & & NUMBER & PERCENTAGE \\
\hline \multirow{2}{*}{ GENDER } & MALE & 39 & 65 \\
\hline & FEMALE & 21 & 35 \\
\hline \multirow{3}{*}{ SMOKING } & YES & 25 & 42 \\
\hline & NO & 23 & 38 \\
\hline & EX-SMOKER & 12 & 20 \\
\hline
\end{tabular}

Table 3: Comparison of FVC, $\mathrm{FEV}_{1}, \mathrm{FEV}_{1} / \mathrm{FVC}$ and MVV Pre and Post diaphragmatic breathing

\begin{tabular}{|l|l|l|l|l|l|}
\hline \multirow{2}{*}{ PARAMETERS } & MEAN \pm SD & \multirow{2}{*}{ t- VALUE } & \multirow{2}{*}{ p- VALUE } & \multirow{2}{*}{ INTERPRETATION } \\
\cline { 2 - 3 } & PRE & POST & & \\
\hline FVC (L) & $2.15 \pm 0.50$ & $2.42 \pm 0.54$ & 11.575 & 0.001 & Significant \\
\hline FEV $_{\mathbf{1}}$ (L) & $1.39 \pm 0.36$ & $1.59 \pm 0.40$ & 22.464 & 0.001 & Significant \\
\hline FEV $_{\mathbf{1}} / \mathbf{F V C}(\%)$ & $64.28 \pm 3.66$ & $64.40 \pm 3.69$ & 1.224 & 0.226 & Not significant \\
\hline MVV (L/min) & $55.51 \pm 14.53$ & $63.43 \pm 15.87$ & 22.464 & 0.001 & Significant \\
\hline
\end{tabular}

Table 4: Comparison of FVC, $\mathrm{FEV}_{1}, \mathrm{FEV}_{1} / \mathrm{FVC}$ and MVV Pre and Post inverse ratio breathing

\begin{tabular}{|l|l|l|l|l|l|}
\hline \multirow{2}{*}{ PARAMETERS } & \multicolumn{2}{|l|}{ MEAN \pm SD } & \multirow{2}{*}{ t- VALUE } & \multirow{2}{*}{ p- VALUE } & \multirow{2}{*}{ INTERPRETATION } \\
\cline { 2 - 5 } & PRE & POST & & \\
\hline FVC $(\mathbf{L})$ & $2.15 \pm 0.49$ & $2.16 \pm 0.50$ & 1.078 & 0.285 & Not significant \\
\hline FEV $_{\mathbf{1}}(\mathbf{L})$ & $1.39 \pm 0.36$ & $1.39 \pm 0.36$ & 0.700 & 0.487 & Not significant \\
\hline FEV $_{\mathbf{1}} / \mathbf{F V C}(\%)$ & $64.28 \pm 3.66$ & $64.37 \pm 3.55$ & 1.150 & 0.255 & Not significant \\
\hline MVV (L/min) & $55.59 \pm 14.30$ & $55.70 \pm 14.35$ & 0.700 & 0.487 & Not significant \\
\hline
\end{tabular}


Bharvi Malavia et.al. A study to compare the immediate effects of inverse ratio breathing and diaphragmatic breathing on pulmonary functions and thoracic expansion in patients with chronic obstructive pulmonary disease.

Table 5: Between technique comparison of $\mathrm{FVC}, \mathrm{FEV}_{1}, \mathrm{FEV}_{1} / \mathrm{FVC}$ and $\mathrm{MVV}$ of Diaphragmatic breathing and Inverse ratio breathing

\begin{tabular}{|l|l|l|l|l|l|}
\hline \multirow{2}{*}{ PARAMETERS } & MEAN \pm SD & \multirow{2}{*}{ t- VALUE } & \multirow{2}{*}{ p- VALUE } & \multirow{2}{*}{ INTERPR-ETATION } \\
\cline { 2 - 5 } & Diaphragmatic breathing & Inverse ratio breathing & & & \\
\hline FVC $(\mathbf{L})$ & $0.30 \pm 0.13$ & $0.03 \pm 0.03$ & 15.300 & 0.000 & Significant \\
\hline FEV $_{\mathbf{1}}$ (L) & $0.20 \pm 0.07$ & $0.02 \pm 0.02$ & 19.191 & 0.000 & Significant \\
\hline FEV $_{\mathbf{1}}$ FVC (\%) & $0.48 \pm 0.57$ & $0.28 \pm 0.49$ & 2.066 & 0.041 & Significant \\
\hline MVV (L/min) & $7.92 \pm 2.73$ & $0.88 \pm 0.79$ & 19.191 & 0.000 & Significant \\
\hline
\end{tabular}

Table 6: Comparison of thoracic expansion pre and post Diaphragmatic breathing

\begin{tabular}{|l|l|l|l|l|l|}
\hline \multirow{2}{*}{ PARAMETERS } & MEAN \pm SD & \multirow{2}{*}{ Z- VALUE } & p- VALUE & INTERPRETATION \\
\cline { 2 - 5 } & PRE & POST & & \\
\hline $\mathbf{2}^{\text {nd }}$ ICS $(\mathbf{c m})$ & $1.38 \pm 0.67$ & $1.43 \pm 0.69$ & 1.807 & 0.071 & Not significant \\
\hline $\mathbf{4}^{\text {th }} \mathbf{I C S}(\mathbf{c m})$ & $2.29 \pm 0.81$ & $2.35 \pm 0.89$ & 1.436 & 0.151 & Not significant \\
\hline $\mathbf{6}^{\text {th }} \mathbf{I C S}(\mathbf{c m})$ & $1.03 \pm 0.44$ & $1.08 \pm 0.43$ & 1.732 & 0.083 & Not significant \\
\hline
\end{tabular}

Table 7: Comparison of thoracic expansion before and after Inverse ratio breathing

\begin{tabular}{|l|l|l|l|l|l|}
\hline \multirow{2}{*}{ PARAMETERS } & \multicolumn{2}{|l|}{ MEAN \pm SD } & \multirow{2}{*}{ Z- VALUE } & \multirow{2}{*}{ p- VALUE } & INTERPRETATION \\
\cline { 2 - 5 } & PRE & POST & & & \\
\hline $\mathbf{2}^{\text {nd }} \mathbf{I C S}(\mathbf{c m})$ & $1.41 \pm 0.65$ & $1.47 \pm 0.70$ & 1.658 & 0.097 & Not significant \\
\hline $\mathbf{4}^{\text {th }} \mathbf{I C S}(\mathbf{c m})$ & $2.31 \pm 0.80$ & $2.39 \pm 0.89$ & 1.801 & 0.072 & Not significant \\
\hline $\mathbf{6}^{\text {th }} \mathbf{I C S}(\mathbf{c m})$ & $1.04 \pm 0.41$ & $1.07 \pm 0.45$ & 0.775 & 0.439 & Not significant \\
\hline
\end{tabular}

Table 8: Between technique comparison of thoracic expansion of Diaphragmatic breathing and Inverse ratio breathing

\begin{tabular}{|l|l|l|l|l|l|}
\hline \multirow{2}{*}{ PARAMETERS } & MEAN \pm SD & \multirow{2}{*}{ U- VALUE } & p- VALUE & \multirow{2}{*}{ INTERPR-ETATION } \\
\cline { 2 - 6 } & Diaphragmatic breathing & Inverse ratio breathing & & & \\
\hline $\mathbf{2}^{\text {nd }} \mathbf{I C S}(\mathbf{c m})$ & $0.05 \pm 0.22$ & $0.05 \pm 0.24$ & 0.180 & 0.857 & Not significant \\
\hline $\mathbf{4}^{\text {th }} \mathbf{I C S}(\mathbf{c m})$ & $0.05 \pm 0.29$ & $0.07 \pm 0.42$ & 0.281 & 0.779 & Not significant \\
\hline $\mathbf{6}^{\text {th }} \mathbf{I C S}(\mathbf{c m})$ & $0.04 \pm 0.20$ & $0.02 \pm 0.23$ & 0.045 & 0.964 & Not significant \\
\hline
\end{tabular}

\section{DISCUSSION}

This study was conducted to compare the immediate effects of inverse ratio breathing and diaphragmatic breathing on pulmonary functions and thoracic expansion in patients with chronic obstructive pulmonary disease.

The result showed that FVC, $\mathrm{FEV}_{1}$ and MVV improved significantly after diaphragmatic breathing. But $\mathrm{FEV}_{1} / \mathrm{FVC}$ ratio and thoracic expansion was not significantly improved. Whereas after performing inverse ratio breathing, the pulmonary functions and thoracic expansion showed no significant improvement in patients with COPD.

It is known that diaphragmatic dysfunction is an important deleterious consequence of the progression of the severity of COPD. With the increase in air flow resistance, air trapping, and hyperinflation in this disease, the inspiratory muscles are passively shortened and placed at a mechanical disadvantage $[21,22]$. Therefore, a progressive reduction occurs in the mobility of the diaphragm and in its relative contribution to thoracoabdominal movement ${ }^{[23,24,25]}$, and as a compensatory mechanism, there is greater recruitment of the respiratory muscles of the rib cage ${ }^{[26,27]}$. In this context, both the reduction in diaphragm mobility and the greater activity of the rib cage respiratory muscles are associated with the increase in dyspnea and intolerance to physical exercise ${ }^{[28,29,30]}$

To reduce or minimize these alterations, studies have been conducted with diaphragmatic breathing as a form of therapy for improving diaphragmatic mobility and thereby reducing the deleterious effects of diaphragmatic dysfunction.

Diaphragmatic breathing was beneficial to the COPD patients because it promoted an increase in the lung volumes, which is in agreement with the proposal of Cahalin et al ${ }^{[12]}$. Diaphragmatic breathing is frequently applied in pulmonary rehabilitation programs, and its efficacy in improving pulmonary functions has been documented ${ }^{[29,31]}$. In the present study, the beneficial effects of diaphragmatic breathing on pulmonary functions were also observed when compared with inverse ratio breathing.

The increases in pulmonary volume during the breathing exercises were due to significant increases in end-inspiratory rib- 
Bharvi Malavia et.al. A study to compare the immediate effects of inverse ratio breathing and diaphragmatic breathing on pulmonary functions and thoracic expansion in patients with chronic obstructive pulmonary disease.

cage volume and end-inspiratory abdomen volume, without changes in the endexpiratory chest wall volume. Other studies also reported significant increases in tidal volume during diaphragmatic breathing ${ }^{[31,}$ 32, 33]. The increase in volume associated with the increase in the end-inspiratory chest wall volume indicated that the subjects were able to recruit the inspiratory reserve volume. The same result was observed in the study by Fernandes et al ${ }^{[31]}$ in a specific group of subjects with COPD who also presented significant increases in tidal volume but no changes in end-expiratory volume.

Inverse ratio breathing technique differs to a great extent from that of diaphragmatic breathing. To perform the exercises of the inverse ratio breathing, it is necessary to breathe deeply at I: E ratio of $4: 1$ which mainly requires the use of the upper chest. The subjects used the accessory muscles more than the diaphragm, showing thoracic respiration by raising their shoulders or moving their chests for excessive inhalation and exhalation. Such result is consistent with that of the study in which breathing exercise using threshold device did not induce changes in diaphragmatic activities but significantly increase activities of the sternocleidomastoid muscle ${ }^{[27]}$.

Therefore, as respiration is a little restricted because no movement occurs in the abdominal compartment, the results of this study showed that after inverse ratio breathing, there were no changes in the pulmonary volumes, unlike after diaphragmatic breathing, in which there is a diaphragmatic excursion with abdominal projection. This more restricted respiratory movement in inverse ratio breathing did not promote alteration in any respiratory patterns evaluated in the individuals with COPD in the present study.

A study conducted by Kshipra et al., ${ }^{[16]}$ to find the immediate effects of inverse ratio breathing versus diaphragmatic breathing on inspiratory vital capacity and thoracic expansion in adult healthy females suggested a significant increase in lung volumes and thoracic expansion in both the breathing techniques. Thus, because the movement of the rib cage is greater in the healthy subjects, this was probably detected in the healthy individuals.

Inverse ratio breathing causes breath stacking (creating auto PEEP), as the patient is unable to completely exhale a breathe before the next inspiratory phase begins, resulting in elevated airway pressure. It may potentiate this process due to relatively short expiratory time. The auto PEEP effect may benefit the oxygenation; however, the increased pressure may exacerbate lung stress.

With regard to chest wall expansion, although there was improvement after diaphragmatic breathing exercises in pulmonary functions, however, there was no increase in the chest mobility. It is known that subjects with COPD have diminished diaphragmatic motion and a lower diaphragmatic excursion, $[25,30]$ and, depending on the severity of these alterations, this may interfere with the response to diaphragmatic breathing, [31] which limits the involvement of chest mobility. In fact, some studies that assessed the effects of pursed-lips breathing showed an increase in the tidal volume in both the rib cage and the abdomen; however, the contribution of the compartments to the chest wall was not analyzed ${ }^{[34,35]}$.

The present study is a short-term one and its conclusions must be confirmed by long-term studies. Whether the acute physiological effects can be offset in the long-term by more favourable effects remains to be established. As a matter of fact, the detrimental effects observed by Gosselink et al., ${ }^{[36]}$ with diaphragmatic breathing were not permanently present during natural breathing, thus indicating that the diaphragmatic breathing pattern was not adopted as the natural pattern. Nevertheless, short-term studies are required before longer-term investigation of therapeutic interventions, in order to show at least the tolerance of the patients to the treatment. 
Bharvi Malavia et.al. A study to compare the immediate effects of inverse ratio breathing and diaphragmatic breathing on pulmonary functions and thoracic expansion in patients with chronic obstructive pulmonary disease.

\section{CONCLUSION}

From this study, it can be concluded that a single session of diaphragmatic breathing showed significant improvement in pulmonary functions, however no improvement was observed in thoracic expansion. Whereas inverse ratio breathing showed no improvement in pulmonary functions or thoracic expansion.

The results of this study i.e. diaphragmatic breathing which showed significant improvement in pulmonary functions has important clinical implications for symptom management in individuals with COPD. The assessed breathing exercises i.e. diaphragmatic breathing was demonstrated to improve pulmonary volumes and hence improves oxygenation. Therefore, these exercises might be helpful for individuals who feel anxious and tense when it is difficult to breathe, as well as for individuals trying to manage sudden COPD symptoms. The exercises may play a role in care and symptom management, and thus may be taught in pulmonary rehabilitation and nursing care programs, and be included in routine care of individuals with COPD.

As it occurs in patients with COPD, in which the breathing pattern is reversed (i.e. increased inspiratory time and reduced expiratory time) which also occurs in inverse ratio breathing, has to be corrected by teaching the patient diaphragmatic breathing technique.

\section{Limitation}

- Study duration of the treatment protocol was short.

- Control group was not taken in the study.

- Only stable patients with COPD were included, therefore these results cannot be generalised to other population groups, including patients with COPD in acute pulmonary exacerbations.

\section{Future recommendation}

- Treatment can be given for longer duration with follow up.
- Other pulmonary function parameters and outcomes like PEFR, respiratory rate, $\mathrm{SPO}_{2}, \mathrm{ABG}$ analysis and dyspnea scale can be used.

\section{ACKNOWLEDGEMENT}

Here, I take this opportunity to express my heartfelt thanks to my respected guide for all her guidance, support and constant encouragement. I would also like to express my gratitude to all the staff members of S.B.B. College of Physiotherapy for their timely help, invaluable guidance and constant support. I am also very thankful to my subjects for their co-operation throughout my study.

\section{Conflict of Interest: None}

\section{Source of Funding: None}

\section{Ethical Approval: Approved}

\section{REFERENCES}

1. Celli BR, MacNee W, Force AET. Standards for the diagnosis and treatment of patientswith COPD: a summary of the ATS/ERS position paper. The European respiratory journal. Jun 2004;23(6):932-946.

2. Mannino DM. chronic Obstructive Pulmonary Disease: definition and epidemiology. Respir Care. 2003 Dec; 489120: 1185-91; discussion 91-3.

3. Viegi G, Pistelli F, Sherrill DL, Maio S, Baldacci S, Carrozzi L. Definition, epidemiology and natural history of COPD. EurRespir J. 2007 Nov;30(5):993-1013.

4. Snider GL. Chronic Obstructive Pulmonary Disease: risk factors, Pathophysiology and pathogenesis. Annu Rev Med. 1989;40:41129.

5. Lopez AD, Mathers CD, Ezzati M, Jamison DT, Murray CJ. Global and regional burden of disease and risk factors, 2001: systematic analysis of population health data. Lancet 2006; 367:1747-1757

6. Niederlander E. Cause of death in the EU. Statistics in focus - Population and social conditions. Eurostat (European Communities) 2006; 101: 1-12.

7. ICMR-PHFI-IHME (2017) India : Health of the Nation's States. 
Bharvi Malavia et.al. A study to compare the immediate effects of inverse ratio breathing and diaphragmatic breathing on pulmonary functions and thoracic expansion in patients with chronic obstructive pulmonary disease.

8. Carla $\mathrm{M}$ et al, Reliability of chest wall mobility \& its correlation with pulmonary functions in pts with copd. Respiratory care.2009; 54(12).

9. Michael TP, Michelle W, Helen S, Paratz JD. Muscle stretching techniques increases vital capacity and range of motion in patients with chronic obstructive pulmonary disease. Arch Phys Med Rehab 2008; 89:1103-1107.

10. Ito M, Kakizaki F, Tsuzura Y, Yamada M. Immediate effect of respiratory muscle stretch gymnastics and diaphragmatic breathing on respiratory pattern. Respiratory Muscle Conditioning Group. Intern Med 1999;38(2):126-32.

11. Courtney R. The functions of breathing and its dysfunctions and their relationship to breathing therapy.Int $\mathrm{J}$ Osteopath Med 2009;12:78-85.

12. Cahalin, L.P., Braga, M., Matsuo, Y. \& Hernandez, E.D., 2002, 'Efficacy of diaphragmatic breathing in persons with chronic obstructive pulmonary disease: A review of the literature', Journal of Cardiopulmonary Rehabilitation 22(1), 721. http://dx.doi. org/10.1097/00008483200201000-00002

13. Yamaguti, W.P., Claudino, R.Cet al., 2012, 'Diaphragmatic breathing training program improves abdominal motion during natural breathing in patients with chronic obstructive pulmonary disease: A randomized controlled trial', Archives of Physical Medicine and Rehabilitation 93(4), 571-577.

http://dx.doi.org/10.1016/j.apmr.2011.11.02 6

14. Chang DW. Clinical Application of Mechanical Ventilation.3rd edition; 2009.

15. Chan K, Abraham E. Effects of inverse ratio ventilation on cardiorespiratory parameters in severe respiratory failure. Chest. 1992 Nov; 102(5):1556-61.

16. KshipraBabanPedamkar, \&Aditi L. Soman.(2016). Immediate effects of inverse ratio breathing versus diaphragmatic breathing on inspiratory vital capacity and thoracic expansion in adult healthy females. International Journal of Physiotherapy, 3(2), 177-181.

17. Zavala E, Ferrer M, Polese G, Masclans JR et al. Effect of inverse I:E ratio ventilation on pulmonary gas exchange in Acute
Respiratory Distress Syndrome. Anesthesiology. 1998;88(1):35-42.

18. Richa, Rajeev Aggarwal, Md.AbuShaphe, Chacko George, Anurag Vats. A comparison of flutter device and active cycle of breathing techniques in acute exacerbation of chronic obstructive pulmonary disease patients Richa / Indian Jouanl of Physiotherapy and Occupational Therapy. July - Sept. 2010, VOL 4 NO 3: 60- 64.

19. Miller MR, Hankinson J, Brusasco V, et al. ATS-ERS taskforce : Standardisation of Lung Function Testing. Standardisation of spirometry.EurRespirJ 2005;26:319-38

20. Therapeutic foundation and techniques, sixth edition. Carolyn Kisner and Allen Colby.

21. De Troyer A. Effect of hyperinflation on the diaphragm.EurRespir J. 1997;10(3):708 13. PMid:9073010.

22. Decramer M. Hyperinflation and respiratory muscle interaction. EurRespir J. 1997;10(4):934-41. PMid:9150337.

23. Suga K, Tsukuda T, Awaya H, Takano K, Koike S, Matsunaga $\mathrm{N}$, et al. Impaired respiratory mechanics in pulmonary emphysema: evaluation with dynamic breathing MRI. J MagnReson Imaging. 1999;10(4):510-20. http://dx.doi. org/10.1002/(SICI)1522-

2586(199910)10:4<510::AIDJMRI3> 3.0.CO;2-G

24. Iwasawa T, Kagei S, Gotoh T, Yoshiike Y, Matsushita K, Kurihara H, et al. Magnetic resonance analysis of abnormal diaphragmatic motion in patients with emphysema. EurRespir J. 2002;19(2):22531. PMid:11866002. http:// dx.doi.org/10.1183/09031936.02.00044602

25. Santos Yamaguti WP, Paulin E, Shibao S, Chammas MC, Salge JM, Ribeiro M, et al. Air trapping: the major factor limiting diaphragm mobility in chronic obstructive pulmonary disease patients. Respirology. 2008;13(1):138-44. PMid:18197925. http://dx.doi. $\quad$ org/10.1111/j.14401843.2007.01194.x

26. Martinez FJ, Couser JI, Celli BR. Factors influencing ventilator muscle recruitment in patients with chronic airflow obstruction. Am Rev Respir Dis. 1990;142(2):276- 82. PMid:2382890.

http://dx.doi.org/10.1164/ajrccm/142.2.276 
Bharvi Malavia et.al. A study to compare the immediate effects of inverse ratio breathing and diaphragmatic breathing on pulmonary functions and thoracic expansion in patients with chronic obstructive pulmonary disease.

27. Andrade AD, Silva TN, Vasconcelos H, Marcelino M, Rodrigues-Machado MG, FilhoVC, et al. Inspiratory muscular activation during threshold therapy in elderly healthy and patients with COPD. J Electromyography Kinesiol. 2005;15(6):631-9. PMid:16051499. http:// dx.doi.org/10.1016/j.jelekin.2005.06.002

28. Ward ME, Eidelman D, Stubbing DG, Bellemare F, Macklem PT. Respiratory sensation and pattern of respiratory muscle activation during diaphragm fatigue. J Appl Physiol. 1988;65(5):2181-9. PMid:3209561.

29. Breslin EH, Garoutte BC, Kohlman-Carrieri V, Celli BR. Correlations between dyspnea, diaphragm and sternomastoid recruitment during inspiratory resistance breathing in normal subjects. Chest. 1990;98:(2):298302. PMid:2376161. http://dx.doi.org/ 10.1378/chest.98.2.298

30. Paulin E, Yamaguti WP, Chammas MC, Shibao S, Stelmach R, Cukier A, et al. Influence of diaphragmatic mobility on exercise tolerance and dyspnea in patients with COPD. Respir Med. 2007;101(10):2113-8. PMid:17644365. http://dx.doi.org /10.1016/j. rmed.2007.05.024

31. Marcelo Fernandes, Alberto Cukier and Maria Igne...Efficacy of diaphragmatic breathing in patients with chronic obstructive pulmonary disease. 2011. Chronic Respiratory Disease 8(4) 237244[64] Saud Abdullah Salem Alaudah, Dr. Ahmed Maher, Dr. Ahmed Addelmoniem and Dr.Shahied. Effects of deep diaphragmatic breathing in copdpatients. World journal of pharmacy and pharmaceutical sciences. Volume 6, Issue 5, 1722-1730. 2017.
32. Nici L, Donner C, Wouters E, Zuwallack R, Ambrosino N, Bourbeau J, et al. American Thoracic Society/European Respiratory Society statement on pulmonary rehabilitation. Am J RespirCrit Care Med. 2006;173(12):1390- 413. PMid:16760357. http://dx.doi.org/10.1164/rccm.2005081211ST.

33. Sackner MA, Gonzalez HF, Jenouri G, Rodriguez M. Effects of abdominal and thoracic breathing on breathing pattern components in normal subjects and in patients with COPD. Am Rev Respir Dis 1984; 130: 584-87.

34. Bianchi R, Gigliotti F, Romagnoli I, Lanini B, Castellani C, Binazzi B, et al. Patterns of chest wall kinematics during volitional pursedlip breathing in COPD at rest. Respir Med 2007;101(7):1412- 1418.

35. Bianchi R, Gigliotti F, Romagnoli I, Lanini B, Castellani C, Grazzini M, Scano G. Chest wall kinematics and breathlessness during pursed-lip breathing in patients with COPD. Chest 2004; 125(2):459-465.

36. Gosselink RAAM, Wagenaar RC, Sargeant AJ, Rijswijk H, Decramer MLA. Diaphragmatic breathing reduces efficiency of breathing in chronic obstructive pulmonary disease. Am J RespirCrit Care Med 1995; 151: 1136-42.

How to cite this article: Malavia B, Shah S. A study to compare the immediate effects of inverse ratio breathing and diaphragmatic breathing on pulmonary functions and thoracic expansion in patients with chronic obstructive pulmonary disease. Int J Health Sci Res. 2021; 11(5): 340-348. DOI: https://doi.org/10.52403/ ijhsr.20210553 